\title{
APRESENTAÇÃO \\ A Educação Profissional Técnica de Nível Médio na modalidade EaD: Realizações e Perspectivas da Rede e-Tec Brasil
}

Clovis Nicanor Kassick ${ }^{1}$ Araci Hack Catapan ${ }^{2}$

\section{Introdução}

A extensão territorial e as características demográficas do Brasil demandam políticas educacionais que encontram respostas efetivas na modalidade de Educação a Distância (EaD). A organização da EaD no Brasil, segundo suas normas e critérios de qualidade, oferece à população trabalhadora condições de formação e qualificação profissional, superando desigualdades socioculturais gradativamente pela Rede e-Tec Brasil.

\footnotetext{
${ }^{1}$ Possui Graduação em Faculdade de Educação Técnicas Agrícolas pela Universidade Federal do Rio Grande do Sul-UFRGS (1971) e Graduação em Pedagogia pela Federação de Estabelecimentos de Ensino Superior Em Novo Hamburgo-FEEVALE (1976), Especialização em Administração de Sistemas Educacionais pela Universidade do Vale do Rio dos Sinos - UNISINOS (1979); Mestrado em Educação pela Universidade Federal de Santa CatarinaUFSC (1992) e doutorado em Educação pela Universidade Estadual de Campinas-UNICAMP (2001). Professor Adjunto II aposentado da UFSC, atualmente é professor da Universidade do Sul de Santa Catarina-UNISUL, no Curso de Pedagogia e no Programa de Pós-Graduação-Mestrado em Educação, com ênfase nos fundamentos da Educação, atuando principalmente nos seguintes temas: Formação e profissionalização de professores para a Educação Superior e básica; organização de processos educativos; Educação Profissional Técnica de Nível Médio; EaD e assessoria na elaboração e implantação de Projetos Político-Pedagógicos Institucionais. Desenvolve pesquisa na área de: gestão e organização de processos educativos com enfoque especial na organização escolar libertária, a partir de experiência vivida na Escola Paidéia de Mérida-Espanha; Ensino Superior e Educação Profissional Técnica de Nível Médio. Possui publicações nestas áreas. Leciona nos Cursos de Pedagogia e Mestrado em Educação da Unisul. É avaliador de Cursos cadastrado no SINAES-INEP. Desenvolveu pesquisa de pós-doutorado, como bolsista da Fundación Carolina de Madrid-Espanha (de novembro de 2008 a julho de 2009), intitulada: "A organização de processos educativos na perspectiva autogestionária", junto a Universidade de Valladolid - Valladolid/Espanha e a Universidade Técnica de Lisboa Instituto Superior de Economia e Gestão. É pesquisador associado do Grupo de Investigación sobre desarrollo territorial sostenible, da Facultad de Educación y Trabajo Social de la Universidad de Valladolid-Espanha. É pesquisador do grupo GTMC-UFSC, na pesquisa: Elaboração de Currículos Referência para os Cursos Técnicos da Escola Técnica Aberta do Brasil/ e-Tec Brasil, do E-TEC/SETEC/MEC. E-mail: <kassickclovis@gmail.com>

2 Pós-doutorado - em Memoria organizacional, inovação social e resiliência, pelo centro ALGORITMI/UMINHO/PT (2016); doutorado em Engenharia de Produção - pela Universidade Federal de Santa Catarina (2001); mestrado em Educação e Trabalho pela Universidade Federal de Santa Catarina (1993); Especialista em Currículo e filosofia pela PUCMG. Atualmente é professora na Universidade Federal de Santa Catarina nos programas de Pós-Graduação em Engenharia e Gestão do Conhecimento e em Educação. Atua em pesquisa, ensino e extensão, com ênfase nos seguintes temas: E-learning, cibercultura, Tecnologia de comunicação digital (TCD), educação virtual, Educação a Distância formação de professores, Recursos educativos abertos. Consultora UAB/CAPES e Rede e-Tec Brasil/MEC. É coordenadora dos grupos de pesquisa: Habitats de Inovação e Empreendedorismo e Pesquisa Científica em E-learning do CNPq/MEC. E-mail: <aracihack@gmail.com>
} 
A Educação a Distância oferecida pela Rede e-Tec não só estende a oferta de formação profissional, como atualiza o acesso de uma população, até então excluída, ao mundo da comunicação digital.

A Rede e-Tec Brasil teve início em 2007 com o nome de Sistema e-Tec Brasil, criado pelo decreto 6.301/07, com a finalidade de desenvolver a Educação Profissional e Tecnológica na modalidade de Educação a Distância, ampliando e democratizando a oferta e o acesso à educação profissional pública e gratuita no país. Foi reorganizada, como Rede eTec Brasil, pelo Decreto no 7.589 de 26/10/2011, e passou a constituir uma das ações nacionais do Programa Nacional de Acesso ao Ensino Técnico e Emprego (PRONATEC). 0 PRONATEC foi criado pelo Governo Federal em 2011, por meio da Lei 2.513/2011, para ampliar as oportunidades educacionais e de formação profissional qualificada aos jovens, trabalhadores e beneficiários de programas de transferência de renda.

A Rede e-Tec constitui, portanto, um passo importante para a democratização do acesso à educação profissional técnica na modalidade EaD no Brasil. A Rede e-Tec Brasil pretende atender às necessidades de expansão e inovação na área de Educação Profissional Técnica em nível médio, estendendo a possibilidade de formação e atualização à população que atua ou atuará no mundo do trabalho, e não tem acesso a cursos presenciais. Esse desafio demanda a implementação de ações inovadoras em todas as dimensões da gestão e docência na Rede.

Em 2011, a Rede e-Tec integrava 11 Eixos Tecnológicos em 53 cursos oferecidos por 47 instituições públicas e 483 polos de apoio presencial distribuídos pelo país, atendendo, aproximadamente, 70.000 estudantes. Em dados estimados por Fernando Amorim $^{3}$, coordenador do programa, a rede atendeu aproximadamente 270.000 estudantes de Ensino Técnico de nível médio, em 800 polos de apoio presencial no ano de 2013.

Hoje, por meio da Rede e-Tec Brasil, são oferecidos gratuitamente 165 cursos técnicos e de qualificação profissional na modalidade a distância. Participam 54 instituições da Rede Federal de Educação Profissional, Científica e Tecnológica, 19 instituições de educação profissional vinculadas aos sistemas estaduais e as unidades de ensino dos Serviços Nacionais de Aprendizagem (SENAI, SENAC, SENAR e SENAT).

\footnotetext{
${ }^{3}$ Palestra proferida pelo coordenador Nacional da Rede e-Tec em 28.10.2014, Prof. Fernando Amorim, na abertura do curso de especialização em Gestão e Docência em EaD, na UFSC (www.etec.ufsc.br).
} 
Para a implementação da rede e-Tec, a Secretaria de Educação Profissional e Tecnológica - SETEC, em parceria com Universidades e Institutos, tem promovido ações pontuais de formação, de pesquisa e de acompanhamento e avaliação.

O Grupo de Pesquisa em Educação a Distância - PCEADIS/CNPq da Universidade Federal de Santa Catarina - UFSC, em pareceria com o Fórum Nacional de Educação Profissional Técnica em EaD - FNEAD, tem desenvolvido contínuas ações de capacitação, pesquisa, acompanhamento e avaliação das práticas da Rede e-Tec ${ }^{4}$.

A organização e publicação do Dossiê Poiésis intitulado A Educação Profissional Técnica de Nível Médio na modalidade EaD: Realizações e Perspectivas da Rede e-Tec Brasil, é uma ação em parceria com o PPGE/UNISUL, que dá sequência a todos os demais trabalhos, no sentido de divulgar o que está sendo produzido pelos membros da Rede e-Tec. Além de se incluir e ser concernente com as realizações dos pesquisadores da Rede e-Tec e do FNEAD, é um mecanismo de divulgação e consolidação científica da área de EaD.

Este dossiê, pelos artigos aqui publicados, evidencia parte do intenso trabalho de pesquisa desenvolvido, em nível nacional, sobre a Educação Profissional Técnica de Nível Médio na modalidade EaD, apresentando algumas de suas realizações e perspectivas em relatos de experiências realizadas e ou em realização.

Assim, o texto da Professora Iolanda Bueno de Camargo Cortelazzo, da Universidade Tecnológica Federal do Paraná - UTFPR, apresenta e discute as competências necessárias à empregabilidade; empreendedorismo e inclusão tecnológica, cuja característica essencial se alicerça em uma educação para a autonomia. Após proceder o rastreamento destas competências na literatura internacional de 2016, principalmente através de experiências desenvolvidas nos Estados Unidos e países europeus, analisa a (má)formação de professores e como esta se manifesta e condiciona a (má)formação de

\footnotetext{
${ }^{4}$ Projetos de pesquisa: 1. GTMC: Grupo de Trabalho para Análise de Matrizes Curriculares dos Projetos do Sistema e-Tec (2007 a 2009).2. Projeto de pesquisa para elaboração do Currículo Referência para o sistema eTec Brasil: uma construção coletiva - GPCRFI (2009 a 2011); 3. Projeto de Pesquisa Concepção e Desenvolvimento de uma Metodologia para a Implementação do Currículo Referência- GPCRFII (2011 a 2013); 4. Projeto de pesquisa - Metodologias e experiências exitosa de implementação da Rede e-Tec Brasil (2012 a 2014): Projetos de extensão Cursos: 1. Cursos de capacitação para professores autores, para professores formadores, para gestores. 2: Curso de especialização em Gestão e Docência em EaD: 3. Sistema de Acompanhamento e Avaliação do sistema e-Tec - SAAS (2010 A 2016) todos disponíveis em www.etec.ufsc.br 4. Repositório: Acervo de Recursos Educacional para a Educação Profissional e Tecnológica _PROedu disponível em http://proedu.ifce.edu.br/
} 
alunos, dificultando sua transformação em estudantes, pela impossibilidade de constituíremse em sujeitos autônomos.

No texto Metodologia para elaboração de Matriz Curricular: integração e transversalidade, os autores Araci H. Catapan; Clovis N. Kassick e Valter O. Iriondo, apresentam alguns dos resultados de investigação realizada na aplicação de uma metodologia de elaboração de Matriz Curricular de forma integrada e transversal. Da pesquisa resultaram cinquenta e três matrizes curriculares para cursos profissionais técnicos de nível médio na modalidade EaD, para servir como referência nacional para a organização e implantação daqueles cursos.

Na sequência, Carlos Alberto Dalabona, da UFTPR, no texto intitulado Educação Profissional e Tecnológica, apresenta um breve relato histórico do cenário atual da Educação Profissional e Tecnológica brasileira, para deter-se nos dados atuais do INEP sobre a EPT, de forma a permitir uma análise dos números ali apresentados, contrastando-os com as metas previstas no PNE.

No texto Ensino Técnico Profissionalizante Estudo de caso: Uma proposta de curso técnico da Rede e-Tec Brasil, os autores Adelson de Paula Silva, do CEFET-MG, e Viviane Sartori, da UFSC, fazem um breve relato sobre a educação profissional técnica de nível médio e da $\mathrm{EaD}$, para situar o foco de análise de sua pesquisa, que aborda o curso de Formação de Técnico de Informática para Internet, desenvolvido no CEFET-MG, abordando a estrutura e funcionamento adotado por aquela Instituiçao como garantia da permanência dos estudantes no curso e qualidade da formação.

José Wilson da Costa, da PUC-MINAS; Márcia Gorett Ribeiro Grossi e Elaine Ribeiro da Silva, do CEFET-MG, discutem a metodologia para a produção de materiais didáticos para a EaD, considerando a especificidade desta modalidade de ensino. Para tanto, após breve contextualização sobre a EaD e a Rede e-Tec Brasil, analisam as condições e características que deve possuir o material didático que alicerça a educação na modalidade EaD.

Conhecer o perfil dos estudantes concluintes do curso Técnico em Meio Ambiente, do ciclo 2014-2015, oferecido pelo Instituto Federal de Tocantins - IFTO, na modalidade EaD, nos polos de Araguatins, Colinas do Tocantins, Palmas e Porto Nacional, em Tocantins, foi o objetivo que levou os autores Ana Lúcia Petrocione Jardim; Francisco Gilson 
Rebouças Pôrto Júnior e Madson Teles de Souza a realizar o levantamento que descrevem no texto Evasão e Permanência na Educação a Distancia: fatores que influenciam a permanência de estudantes do Curso Técnico de Meio Ambiente da Rede e-Tec/IFTO. Além disso, o levantamento buscou investigar, também, os fatores que influenciam os estudantes a que permaneçam e concluam o curso ou a que o abandonem.

Walter Ruben Iriondo Otero, da Universidade Federal de Pelotas (UFPel); Marcelo Zaffalon Peter, do Instituto Federal de Educação, Ciência e Tecnologia Sul-riograndense (IFSul); e David Antônio da Costa, da Universidade Federal de Santa Catarina (UFSC), no texto Fatores de êxito para a gestão e a docência na educação profissional e tecnológica a distância, apresentam resultado de pesquisa realizada em vinte e três Instituições de ensino da Rede e-Tec Brasil, na busca de identificar metodologias $e$ experiências exitosas na educação profissional técnica de nível médio, tendo como norte a questão: quais ações, fatores, condições que de fato promovem o êxito em gestão e docência nas Instituições da rede e-Tec Brasil? A pesquisa balizou-se no trabalho desenvolvido pelo tutor presencial, tutor a distancia, professor, Coordenador geral, coordenador de curso e equipe multiprofissional e coordenador de polo. O levantamento de dados aponta as circunstancias nas quais os cursos, na modalidade EaD, possuem mais chances de sucesso na sua conclusão pelos estudantes.

O texto intitulado $A$ concepção de organização do processo educativo na Educação Profissional na modalidade EaD, de Karolina da Silva Cabral e Clovis N. Kassick, discute a triangulação necessária para que o direito à educação se efetive para a população brasileira. Trazendo elementos do PNE sobre a necessidade de triplicar as matrículas na educação profissional técnica de nível médio, ao mesmo tempo em que assegura qualidade na oferta, discute a organização do processo educativo a partir de seu ancoramento teórico em princípios pedagógicos cognitivistas. Para tanto, dirige o olhar para experiência realizada no curso técnico de automação industrial na modalidade EaD do SENAI/SC, no que diz respeito a sua organização didática como condição de assegurar, aos estudantes, uma aprendizagem significativa na perspectiva de uma educação de qualidade e cidadã.

O texto de Maria Hermínia Lage Fernandes Laffin e Morgana Zardo von Mecheln analisa as políticas públicas expressas nos documentos legais, concernentes à percepção da vinculação entre educação profissional e o mundo do trabalho, em especial, os destinados 
ao PROEJA. Nesta perspectiva, analisa a constituição federal, no que diz respeito à educação profissional; a LDB de 96, além de Portarias Ministeriais e demais legislação. O foco do trabalho são as percepções e princípios que alicerçam o PROEJA, dentre eles, o modo próprio da educação, considerada em relação a clientela; a formação para a cidadania e o trabalho como princípio educativo.

A publicação desse Dossiê contribui para a consolidação da pesquisa em Educação a Distância, que se amplia e se aprofunda como uma nova área de conhecimento no campo de Educação. As contribuições apresentadas abrem-se para novas pesquisas, instigando a comunidade da Educação Profissional Tecnológica, congregada pelas práticas de educação a Distância, ampliar e aprofundar a discussão, tendo como objeto a Rede e-Tec Brasil e suas práticas abertas e generalizáveis.

Os organizadores. 